\title{
Lipid Peroxidation and Superoxide Dismutase-1 and Glutathione Peroxidase Activities in Trisomy 16 Fetal Mice and Human Trisomy 21 Fibroblasts
}

\author{
K. GO̊RAN ANNERÉN AND CHARLES J. EPSTEIN \\ Departments of Pediatrics and Biochemistry and Biophysics, University of California, \\ San Francisco, California 94143
}

\begin{abstract}
An increase in lipid peroxidation has been reported in fetal human trisomy 21 brains. To determine whether this change can be regarded as a consequence of the increase in soluble $\mathrm{Cu}, \mathrm{Zn}$-superoxide dismutase (SOD-1) activity caused by the trisomy, we have made use of the trisomy 16 mouse, a model for human trisomy 21. Lipid peroxidation, as malonaldehyde, and the activities of SOD-1 and glutathione peroxidase were studied in diploid and trisomy 16 mouse fetuses and fetal brains and, for comparison, in diploid and trisomy 21 human fibroblasts. SOD-1 activity in diploid mouse brain increased during fetal and postnatal development, but glutathione peroxidase activity was unchanged. Mean SOD-1 activity was almost exactly 50\% increased in trisomy 16 fetuses and fetal brains and in human trisomy 21 fibroblasts, confirming the gene dosage effect in both species. The SOD-1 activity in the trisomic fetuses was correlated with that in their matched diploid littermates, suggesting that factors other than the gene dosage also determine activity. Mean glutathione peroxidase activity was not increased in trisomy 16 fetuses or brains and only slightly increased in human trisomy 21 fibroblasts. Mean lipid peroxidation was decreased in fetal trisomy 16 brains but was increased in human trisomy 21 fibroblasts. These results do not lend support to the notion that increased SOD-1 activity is developmentally deleterious and necessarily increases lipid peroxidation and, secondarily, the activity of glutathione peroxidase. The difference between the human and mouse data concerning lipid peroxidation in trisomic brains may be related to structural differences in the lipids which provide the substrate for lipid peroxidation. (Pediatr Res 21: 88-92, 1987)
\end{abstract}

\section{Abbreviations}

DS, Down syndrome

SOD-1, soluble superoxide dismutase, $\mathrm{Cu}, \mathrm{Zn}$-superoxide dismutase

GSH-Px, glutathione peroxidase

Received July 17, 1986; accepted September 10, 1986

Correspondence to Charles J. Epstein, M.D., Department of Pediatrics, University of California, San Francisco, CA 94143-0106.

Supported by Grant HD-17001 from the National Institute of Child Health and Human Development. K.G.A. was supported by grants from the Swedish Medical Research Council, the Sävstaholm Society, the Swedish Institute, the Fulbright Commission, the Swedish Medical Association, the Sweden American Foundation, the Sven Jerring-Bo Wahlqvist Foundation, and the Medical Faculty of the University of Uppsala. Sweden.
MDA, malonaldehyde

TBA, thiobarbituric acid

PUFA, polyunsaturated fatty acids

$\mathrm{O}_{2}^{-}$, superoxide

$\mathrm{H}_{2} \mathrm{O}_{2}$, hydrogen peroxide

$\mathrm{OH} \cdot$, hydroxyl radical

NBT, nitroblue tetrazolium

Chemically reactive oxygen radicals and compounds, including $\mathrm{O}_{2}^{-}, \mathrm{H}_{2} \mathrm{O}_{2}$, and $\mathrm{OH} \cdot$, are generated during normal cellular metabolism and after exposure to external agents such as radiation and certain chemicals. All living sells exposed to oxygen have enzymatic systems for protection against activated oxygen, and SOD-1 and GSH-Px are members of these systems. SOD-1, a soluble $\mathrm{Cu}-\mathrm{Zn}$ enzyme, is coded for by human chromosome 21 , and individuals with DS have a $50 \%$ increase in SOD-1 activity. Among the cells and tissues studied have been erythrocytes (1), fibroblasts (2), platelets (3), lymphocytes (2), and fetal brain (4).

SOD-1 catalyses the dismutation of $\mathrm{O}_{2}{ }^{-}$to form $\mathrm{H}_{2} \mathrm{O}_{2}$ which, in turn, is reduced to water by catalase and peroxidases, especially GSH-Px. However, $\mathrm{H}_{2} \mathrm{O}_{2}$ can also react with $\mathrm{O}_{2}^{-}$to generate the hydroxyl radical which may be the most injurious of the oxygen metabolites. Because of the central role of SOD-1 in the generation of $\mathrm{H}_{2} \mathrm{O}_{2}$, it has been suggested that the increased SOD-1 activity in human trisomy 21 could result in an increased generation of $\mathrm{H}_{2} \mathrm{O}_{2}$ and, as a consequence, in increased lipid peroxidation $(5,6)$. Lipid peroxidation has been implicated in the causation of damage to membrane and other cellular structures with high contents of unsaturated lipids, thereby leading to progressive tissue damage. The most vulnerable organ is probaly the nervous system, which contains a high content of PUFA, and it has been proposed that the appearance of mental retardation and presenile dementia in DS is brought about, in whole or in part, by increased lipid peroxidation in the brain $(5,6)$. As evidence in support of this idea, Sinet and coworkers $(3,5)$ and Annerén et al. (7) demonstrated an increase in the activity of GSH-Px, an inducible enzyme coded for by human chromosome 3 , in trisomy 21 erythrocytes and lymphoid cells. Such increases have also been shown by Frischer et al. (8), Néve et al., (9) and Björkstén et al. (10) and in fibroblasts by Sinet et al. (11) but not by Feaster et al., (2). Furthermore, Mayes et al. (12) claimed that cell death and lipid peroxidation were increased in trisomy 21 fibroblasts exposed to high oxygen tension, and Elroy-Stein et al. 
(13) have observed increased lipid peroxidation in established cell lines transfected with a cloned human SOD-1 gene.

In a recent study, Brooksbank and Balazs (4) reported a 50\% elevation in lipid peroxidation in the brains of human fetuses with trisomy 21 as compared with controls. However, because the trisomic brains had an increased ratio of $n-3$ to $n-6$ fatty acids compared to diploid brains (14), the significance of the observed increase in lipid peroxidation is uncertain. Furthermore, in contrast to the results obtained using erythrocytes and lymphoid cells mentioned above, GSH-Px activity was not increased in the fetal brain.

The detailed analysis of the development and biochemistry of the aneuploid human brain is, for many reasons, very difficult, and we have therefore made use of animal model systems to study the pathogenesis of the effects of chromosome imbalance $(15,16)$. Of particular interest with regard to human trisomy 21 is the trisomy 16 mouse fetus which, because several loci which map to human chromosome 21 are located on chromosome 16 in the mouse, serves as an animal model of the human trisomy (17). These loci include superoxide dismutase-1 (SOD-1) (18, $19)$, the interferon- $\alpha / \beta$ receptor $($ IFNRA or IFRC) $(18,19)$, phosphoribosylglycinamide synthetase (PRGS) (20), and the oncogene ETS2 (21). Mouse fetuses with trisomy 16 survive until 18-19 days of gestation and have been used for a variety of studies on cardiac, immunological, and neurological development (22-26).

The aim of the present study was to investigate lipid peroxidation and the activity of SOD-1 and GSH-Px in trisomy 16 fetuses, especially in the brain, so as to determine whether the changes in lipid peroxidation observed in fetal human trisomy 21 brains can be regarded as a general effect of elevated SOD-1 activity. Since there are developmental delays in trisomy 16 fetuses compared to diploid littermates (27), the developmental variation in SOD-1 and GSH-Px activities in normal diploid mouse brain of different gestational ages was also evaluated. In addition, in order to compare the results in mouse trisomy 16 with those in human trisomy 21 , the activities of SOD-1 and GSH-Px and the amount of lipid peroxidation were studied in matched sets of human trisomy 21 and diploid fibroblasts.

\section{MATERIALS AND METHODS}

Breeding of mice and preparation of tissues. Male mice, doubly heterozygous for two different Robertsonian translocation chromosomes, $R b(16.17) 32 L u b$ and $R b(11.16) 2 H$, each of which contains chromosome 16 within a metacentric chromosome, were mated to superovulated CD1 female mice containing a normal set of acrocentric chromosomes to generate trisomy 16 fetuses and littermate controls $(23,28)$. After 14 or 17 days of gestation, the pregnant mice were sacrificed and the trisomic fetuses were identified by their phenotypic abnormalities, including reduced size and massive edema (17). The whole embryo or fetal brain was homogenized in ice-cold Tris- $\mathrm{HCl}$ buffer $(50 \mathrm{nM}$, $\mathrm{pH} 7.6)$ at a tissue to buffer ratio of 19:1 (w/v) (2-4 mg protein/ $\mathrm{ml})$. Protein was measured according to the method of Lowry $e t$ al. (29).

Fibroblast cultures. The fibroblast stains used have been previously described (30). They were obtained from skin biopsies or autopsy specimens of fetuses and were stored at $-160^{\circ} \mathrm{C}$ prior to use. Strains 306 (trisomic) and 307 (diploid) were derived from siblings, strains 255 (diploid) and 256 (trisomic) were derived from a pair of unrelated aborted fetuses matched for gestational age, and strains 152 (diploid) and 153 (trisomic) were from aborted fetal dizygotic twins. Cells were grown in Dulbecco modified Eagle medium (Gibco, Grand Island, NY) containing $10 \%$ fetal calf serum, gentamycin $(0.1 \mathrm{ml} / 100 \mathrm{ml})$, and glutamine $(1 \mathrm{ml} / 100 \mathrm{ml})$ in $5 \% \mathrm{CO}_{2}$ at $37^{\circ} \mathrm{C}$. The cells were harvested at $70-100 \%$ confluence and were washed three times in saline solution.

SOD-1 assays. SOD-1 was assayed for its ability to inhibit the superoxide-mediated reduction of NBT according to the method of Salin and McCord (31) and Fried (32). The reaction mixture, in a total volume of $300 \mu \mathrm{l}$, consisted of $0.02 \mathrm{M}$ sodium bicarbonate $(\mathrm{pH} 10.0), 0.013 \mathrm{mM}$ xanthine $3 \mu \mathrm{M}$ phenazaine methosulphate, $27 \mu \mathrm{M}$ nitroblue tetrazolium, and 20 to $30 \mu \mathrm{l}$ of cell supernatant. The assay was started by adding $10 \mu \mathrm{l}$ xanthine oxidase at an appropriate dilution to give a change in absorbance of 0.024 to $0.036 \mathrm{OD} \mathrm{U} / \mathrm{min}$. Absorbance was measured at 418 $\mathrm{nm}$ with a Gilford Response spectrophotometer, and the SOD-1 concentration was expressed as $\mathrm{U} / \mathrm{mg}$ of total protein. One unit of enzyme activity is defined as that amount which causes a 50\% inhibition in the NBT reduction rate.

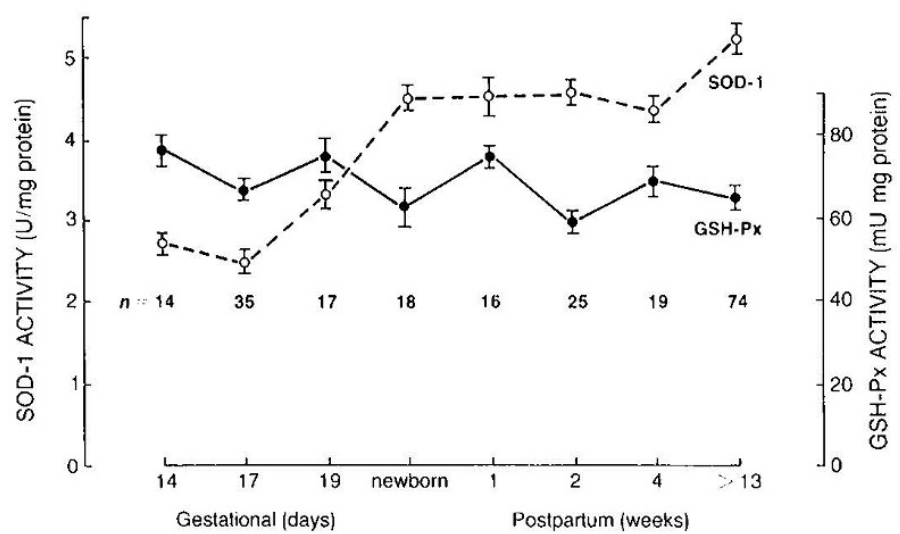

Fig. 1. Developmental pattern of activities (mean \pm SEM) of SOD-1 $(\mathrm{U} / \mathrm{mg}$ protein) and GSH-Px ( $\mathrm{mU} / \mathrm{mg}$ protein) in homogenized brains of normal diploid mice. The number of animals in each group $(n)$ is shown on the figure.

Table 1. Mean levels of SOD-1 (U/mg protein) and GSH-PX (mU/mg protein) in trisomy 16 and diploid fetuses and fetal brains at 14 and 17 days gestation

\begin{tabular}{|c|c|c|c|c|c|c|}
\hline & \multicolumn{2}{|c|}{ Trisomy 16} & \multicolumn{2}{|c|}{ Diploid } & \multirow{2}{*}{$\begin{array}{l}\text { Significance } \\
\text { of difference }\end{array}$} & \multirow{2}{*}{$\frac{\text { Ts16 }}{\text { Diploid }}$} \\
\hline & Mean \pm SEM & $n$ & Mean \pm SEM & $n$ & & \\
\hline Fetal brain & & & & & & \\
\hline \multicolumn{7}{|c|}{14 days gestation } \\
\hline SOD-1 & $4.10 \pm 0.16$ & 14 & $2.71 \pm 0.14$ & 14 & $p<0.001$ & 1.51 \\
\hline GSH-Px & $82.7 \pm 5.5$ & 14 & $77.7 \pm 5.5$ & 14 & NS & 1.06 \\
\hline \multicolumn{7}{|c|}{17 days gestation } \\
\hline SOD-1 & $3.57 \pm 0.18$ & 31 & $2.51 \pm 0.14$ & 42 & $p<0.001$ & 1.42 \\
\hline GSH-Px & $76.7 \pm 4.3$ & 35 & $68.4 \pm 2.3$ & 50 & NS & 1.12 \\
\hline \multirow{2}{*}{\multicolumn{7}{|c|}{$\begin{array}{l}\text { Whole fetus } \\
17 \text { days gestation }\end{array}$}} \\
\hline & & & & & & \\
\hline SOD-1 & $3.71 \pm 0.16$ & 11 & $2.63 \pm 0.15$ & 11 & $p<0.0001$ & 1.41 \\
\hline GSH-Px & $320 \pm 21.6$ & 17 & $316 \pm 10.2$ & 17 & NS & 1.01 \\
\hline
\end{tabular}


GSH-Px assays. GSH-Px activity was assayed by a modification of the method of Paglia and Valentine (33). Reduced glutathione was oxidized by GSH-Px, using cumene hydroperoxide as substrate. The oxidized glutathione was then enzymatically regenerated to the reduced form by glutathione reductase and NADPH. Reaction rates were followed by continuously measuring the decrease in NADPH concentration spectrophotometrically at $340 \mathrm{~nm}$ at $37^{\circ} \mathrm{C}$. The GSH-Px activity was expressed as $\mathrm{mU} / \mathrm{mg}$ of total protein against a bovine GSH-Px standard (Sigma G 6137).

Lipid peroxidation assays. Lipid peroxidation was estimated from the formation of MDA which, together with TBA, forms a colored product (34). Most of the MDA measured in the TBA test is formed from fragmentation of lipid peroxides during incubation at $37^{\circ} \mathrm{C}$ in the presence of ascorbic acid and an iron salt. Baseline values reflect the levels of free MDA and other products present in the sample that absorb at or close to $532 \mathrm{~nm}$ (35). Duplicate samples of $300 \mu \mathrm{l}$ homogenized brain tissue in $50 \mathrm{mM}$ ice-cold Tris- $\mathrm{HCl}$ ( $\mathrm{pH} 7.6$ ) were placed on ice. One of the samples was incubated in a $37^{\circ} \mathrm{C}$ shaking-bath for $30 \mathrm{~min}$ after adding ascorbic acid and $\mathrm{FeSO}_{4}(250$ and $10 \mu \mathrm{M}$ final concentrations, respectively). Baseline levels were obtained by determining the levels of TBA chromogens in samples not treated with heat, ascorbic acid, and ferrous sulphate. To the baseline and incubated samples, $\mathrm{H}_{2} \mathrm{O}(0.9 \mathrm{ml})$ and $28 \%(\mathrm{w} / \mathrm{v})$ trichloroacetic acid $(0.6 \mathrm{ml})$ were immediately added, and the mixtures were centrifuged at once at $3000 \times g$ for $15 \mathrm{~min}$ at $2^{\circ} \mathrm{C}$. The supernatant, $1.38 \mathrm{ml}$, was mixed with $230 \mu \mathrm{l}$ of $1 \% \mathrm{TBA}(\mathrm{w} / \mathrm{v}$ in $50 \mathrm{mM} \mathrm{NaOH}$ ) solution and incubated at $100^{\circ} \mathrm{C}$ for $15 \mathrm{~min}$. Absorbance was measured at $532 \mathrm{~nm}$, and the TBA chromogen concentration was expressed as nmol $\mathrm{MDA} / \mathrm{mg}$ total protein against a standard of malonaldehyde tetraethylacetal (Sigma).

\section{RESULTS}

SOD-1 and GSH-PX activities in fetuses. The developmental changes in activities of SOD-1 and GSH-Px in the brains of normal diploid mice from 14 days of gestation to adulthood are shown in Figure 1. While SOD-1 activity increased about $100 \%$ during the last week of gestation $(p<0.001)$ and then again about $20 \%$ between 4 wk and $\geq 3$ months after birth, GSH-Px activity did not change significantly over the entire period. There were no changes in the SOD-1 or GSH-Px activities between 14 and 17 days of gestation, and this made it possible to compare the results in trisomy 16 fetal brain, which was somewhat delayed in development, with those in diploid fetal littermate brain.

A comparison of SOD-1 and GSH-Px activities in trisomy 16 and diploid fetuses is shown in Table 1. As expected from the increase in SOD-1 gene dosage, mean SOD-1 activity in trisomic brains was increased approximately 1.5 -fold in both trisomic fetal brains at days 14 and 17 of gestation and in whole trisomic fetuses at day 17. However, although the trisomy 16/diploid ratios of mean SOD-1 activities were close to 1.5 , there was a sizable variance on each mean. To determine how much of this is attributable to other genetic and/or environmental factors, the SOD-1 activities of trisomic and diploid littermates were compared. As the data in Figure 2 demonstrate, the variation in SOD-1 activities within each pair of trisomic and matched diploid fetuses are closely correlated, with a correlation coefficient of $0.73(p=0.001)$.

The levels of GSH-Px activity were not significantly different in gestational day 14 and 17 trisomic and diploid brains and in whole fetuses, with the specific activity being about 4.5 -times greater in whole embryos than in brains. There was, however, a large variance within each group which could mask a small difference.

Lipid peroxidation in mouse fetuses. Having demonstrated the increased SOD-1 activities in trisomic brains and whole fetuses, the levels of lipid peroxides, as measured by the production of MDA, were determined, and the results are shown in Table 2.
The mean baseline levels of MDA were the same in day 17 trisomic and diploid fetal brains, while the levels found after incubation with heat, acid, and iron were, surprisingly, significantly decreased $(p<0.001)$ in the trisomic brains.

SOD-1 and GSH-PX activities and lipid peroxidation in human trisomy 21 fibroblasts. A comparison of SOD-1 and GSH-Px activities and MDA formation after incubation with heat, ascorbic acid, and iron in matched sets of human trisomy 21 and diploid fibroblasts is shown in Table 3. The mean SOD-1 activity in trisomic fibroblasts was increased approximately 1.5 -fold $(p$ $<0.0001)$, and the mean GSH-Px activity was increased by 1.18fold $(p<0.05)$. The mean baseline level of MDA was the same in trisomic and diploid fibroblasts, but the level observed after incubation with heat, acid, and iron was 1.55 -fold increased ( $p$ $<0.001$ ) in the trisomy 21 fibroblasts.

\section{DISCUSSION}

The mean SOD-1 activity in trisomy 16 fetal mice is almost exactly $50 \%$ increased compared to that in the control fetuses,

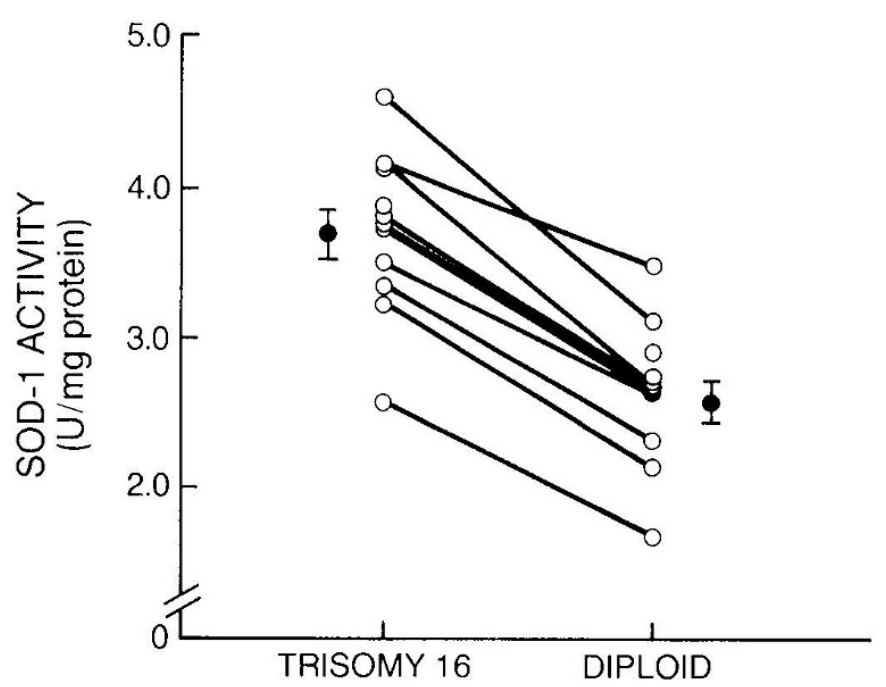

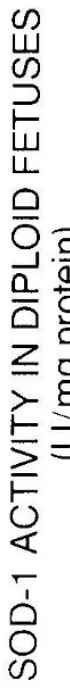

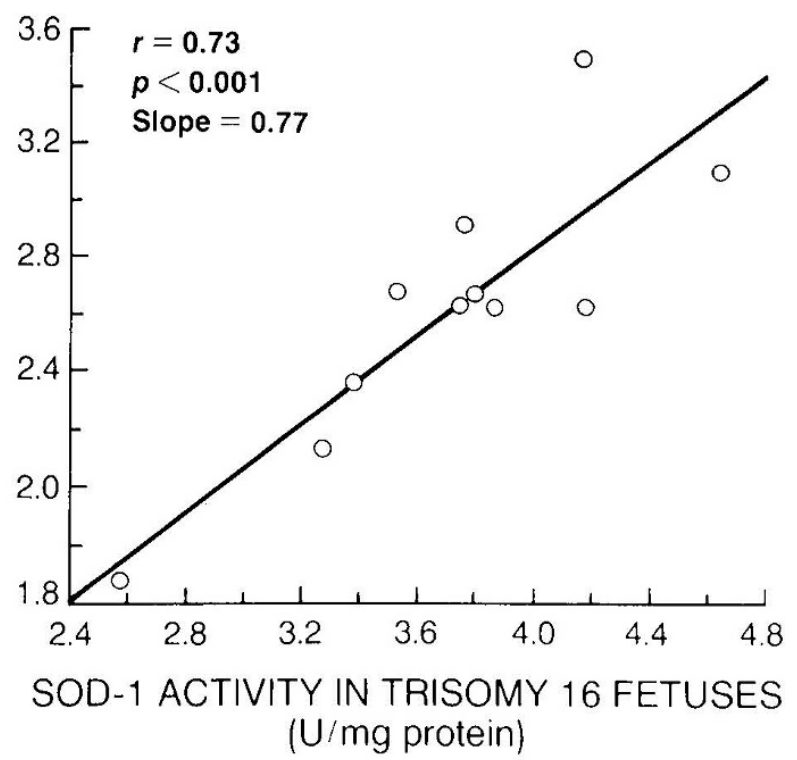

Fig. 2. Top, the SOD-1 activity (U/mg protein) of homogenized whole trisomy 16 and matched littermate fetuses at 17 days gestation. The mean \pm SEM levels of trisomic and littermate diploid fetuses are shown. The difference between the means is significant at $p<0.0001$. Botlom, correlation of SOD-1 activities of Ts16 and diploid fetuses within individual litters. 
Table 2. Mean levels of lipid peroxidation as MDA (nmol/mg protein) in brain homogenates from trisomy 16 and diploid fetuses at 17 days gestation

\begin{tabular}{|c|c|c|c|c|c|}
\hline & \multicolumn{2}{|c|}{ Trisomy 16} & \multicolumn{2}{|c|}{ Diploid } & \multirow{2}{*}{$\begin{array}{l}\text { Significance } \\
\text { of difference }\end{array}$} \\
\hline & Mean \pm SEM & $n$ & Mean \pm SEM & $n$ & \\
\hline Baseline & $4.06 \pm 0.42$ & 23 & $4.12 \pm 0.31$ & 26 & NS \\
\hline
\end{tabular}

Table 3. Mean levels of SOD-1 (U/mg protein), GSH-PX (mU/mg protein), and lipid peroxidation as MDA (nmol/mg protein) in matched pairs of human trisomy 21 and diploid fibroblast strains

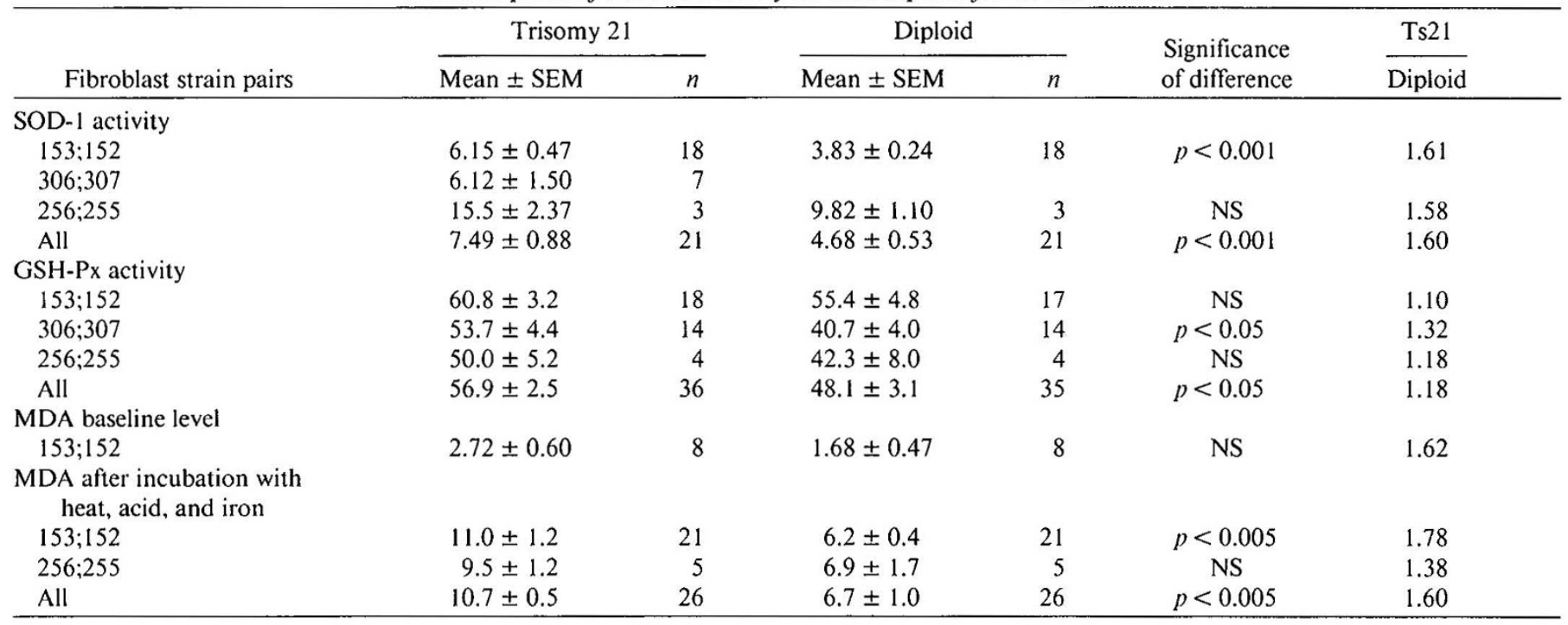

and mean SOD- 1 activity in human trisomy 21 fibroblasts is also very close to 1.5 -fold increased. These findings constitute yet another demonstration of the exactitude with which gene dosage effects operate (16). In addition, these data further confirm the mapping of the SOD-1 gene to mouse chromosome 16. However, our data also suggest that other genetic and/or environmental components determine the levels of SOD-1 activity. There is considerable variance in the SOD-1 activity in whole fetuses, one genetic source of which could be the fact that neither the Robertsonian translocation-carrying males or the CD-1 females are inbred. However, the increased level of SOD-1 activity in individual trisomy 16 fetuses is very closely related to the level observed in their matched diploid littermates, an observation that is consistent with an earlier report (7) of a correlation between the GSH-Px activities in red cells of human trisomic 21 children and their diploid siblings.

We have observed an approximately $100 \%$ increase with age in the mean SOD-1 activity in brains of normal diploid mice. This increase occurs primarily during late gestation, and the SOD-1 activity reaches nearly the adult level by the time of birth. The mechanism underlying the increase in SOD- 1 activity before birth and exposure to an external oxygen challenge is unknown. A similar observation was recently made on GSH-Px activities in rat lung (36). Our finding that the SOD-1 activity in mouse brain changes very little during the first month after birth is in accord with the study of Kellogg and Fridovich (37), although they did observe an approximately 2 -fold increase between 1 and 2 months of age (in A/J and LP/J mice). The constant GSH-Px activity after birth is consistent with findings in postnatal rat brains (38), but once again there was an increase in SOD-1 activity during the 2 nd month of life.

The maturation patterns of SOD-1 and GSH-Px do not follow the same pattern in all organs. Gerdin et al. (36) have recently reported a $135 \%$ increase of GSH-Px in rat lung perinatally, while the SOD-1 activity only increased by $53 \%$ during the same developmental period. They also reported that the periods of increase of SOD-1, GSH-Px, and catalase were not coordinated in time. Differences in the maturation patterns between SOD-1 and GSH-Px systems thus result in altered SOD-1/GSH-Px ratios in cytoplasm at different developmental stages, a result that indicates that the activity of GSH-Px is not necessarily linked to that of SOD-1. There are, unfortunately, no published data concerning the maturation of these two enzyme systems in human brains.

Despite the 1.5-fold increased SOD-1 activity in the brains of trisomy 16 mice, the mean GSH-Px activity was not found to be significantly increased. This result is the same as that reported for human fetal trisomy 21 brain by Brooksbank and Balazs (4). However, in contrast to the further results of these investigators, who found an increased level of lipid peroxidation in the human trisomic brains, we found a decreased level. These findings suggest that an elevation in SOD-1 activity is not necessarily accompanied by either an induction of GSH-Px or an increased level of lipid peroxidation. Why then are the human and mouse data different regarding the latter? The leading possibility is that there are structural differences in the brain lipids which provide the substrate for lipid peroxidation. Thus, as has already been mentioned, Brooksbank et al. (14) have noted an altered pattern of PUFA which could make them more susceptible to lipid peroxidation. Similarly, there may be other genetic or developmental differences between humans and mice which could affect the process. In this regard it is important to realize that mouse chromosome 16 is larger than human chromosome 21 and carries genes that are not present on the latter. Therefore, while SOD-1 activity is similarly increased in both the mouse and human trisomies, other loci may be differential affected in the two species.

A third possibility is that it is a matter of time, with the gestational period of the mouse being too short, especially in view of the relatively low oxygen tensions in fetal tissues, to 
permit the accumulation of significant amounts of lipid peroxides. This would not, however, explain why lipid peroxidation in the fetal trisomic mouse brains was less than normal, unless there were other biochemical differences (such as in lipid composition) between diploid and trisomic fetal brain or the increased SOD-1 activity serves, in this case, to protect the animal against lipid peroxidation. Such an increased protection is what ordinarily would be expected if SOD- 1 really did play a protective role against the deleterious effects of $\mathrm{O}_{2}^{-}$.

The results for GSH-Px in trisomic fetal brain, both human and mouse, and for the whole fetal mouse are at variance with what has been reported for other tissues. As has been mentioned in the introduction, several investigators have observed an increased GSH-Px activity in human trisomic cells, and we have also found a modest increase in our trisomy 21 fibroblasts coupled with an increased level of lipid peroxidation. The reason for this discrepancy between the results in brain and in the other tissues is not clear. One possibility is that GSH-Px is not inducible in the brain, but this would probably not apply to the whole mouse fetus. Another possibility is that the oxygen tension in fetal brain and possibly in the whole fetus is not high enough to trigger the inductive process. While the time required for induction could be an issue in the fetal mouse, this would certainly not apply to the human fetal brain. However, whatever the explanation, our results and those of Brooksband and Balazs (4) indicate, as has already been stated, that increased SOD-1 activity is not necessarily accompanied by an increase in GSH-Px activity.

Because of the possible role of a low tissue oxygen tension in the mouse fetuses in the results obtained, we attempted to stress the system. Accordingly, pregnant mice were put in $95 \% \mathrm{O}_{2}$ during days 11 to 17 of gestation or were exposed, during the same gestational period, to paraquat, a potent superoxide generator, in the drinking water (at a dose of $250 \mathrm{ppm}$ ). In the latter experiment some of the pregnant mice died, but in neither of these two trials did lipid peroxidation or the GSH-Px activity change in the brains of either the pregnant mice or of their trisomy 16 or diploid fetuses.

Our findings with the trisomy 16 mouse fetus do not lend any support to the notion that increased SOD-1 activity is developmentally deleterious. However, it is clear that a limitation of these studies is the fact that we are restricted to the fetal period. Work is now in progress, therefore, to develop transgenic mice with elevated SOD-1 activities which can be used to delineate further the relationships between SOD-1 activity, GSH-Px activity, and lipid peroxidation.

Acknowledgment. The authors thank Teodosia Zamora for valuable assistance in the breeding of animals and Monica Myklebust for assistance in cell culture.

\section{REFERENCES}

I. Sichitiu S. Sinct PM. Lejeune J, Frezal J 1974 Surdosage de la forme dimérique de l'indophénoloxydase dans la trisomie 21, secondaire au surdosage genique. Humangenetik 23:65-72

2. Fcaster WW, Kwok LW. Epstein C 1977 Dosage effects for superoxide dismutase-1 in nucleated cells aneuploid for chromosome 21 . Am J Hum Genet 29:563-570

3. Sinet PM. Michelson AM, Bazin A. Lejeune J, Jerome H 1975 Increase in glutathione peroxidase activity in erythrocytes from trisomy 21 subjects. Biochem Biophys Res Commun 67:910-915

4. Brooksbank BWL, Balazs R 1984 Superoxide dismutase, glutathione peroxidase and lipoperoxidation in Down's syndrome fetal brain. Dev Brain Res $16: 37-44$

5. Sinet PM 1982 Metabolism of oxygen derivatives in Down's syndrome. Ann NY Acad Sci USA 396:83-94

6. Delahunty D, King A, McCormack MK 1982 Oxygen metabolism in Alzheimer"s disease (AD). Am J Hum Genet 34:49A

7. Annerén G, Edqvist L-E, Gebre-Medhin M, Gustavson K-H 1985 Glutathione peroxidase activity in erythrocytes in Down's syndrome. Abnormal variation in relation to age and sex through childhood and adolescence. Trisomy 21 $1: 9-17$
8. Frischer H, Chu LK, Ahmad T, Justice P, Smith GF 1981 Superoxide dismutase and glutathione peroxidase abnormalities in erythrocytes and lymphoid cells in Down syndrome. In: Brewer GJ (ed) The Red Cell: Fifth Ann Arbor Conference. A.L. Liss, New York, 269-283

9. Néve J, Sinet PM, Molle L, Nicole A 1983 Selenium, zinc and copper levels in Down's syndrome (trisomy 21): blood levels and relations with glutathione peroxidase and superoxide dismutase. Clin Chim Acta 133:209-214

10. Björkstén B, Marklund S, Hägglöf B 1984 Enzymes of leucocyte oxidative metabolism in Down's syndrome. Acta Paediatr Scand 73:97-101

11. Sinet PM, Lejeune J, Jerome H 1979 Trisomy 21 (Down's syndrome). Glutathione peroxidase, hexose monophosphate shunt and IQ. Life Sci 24:29-35

12. Mayes J, Muneer R, Sifers M 1984 Superoxide dismutase activity and oxygen toxicity in Down syndrome fibroblasts. Am J Hum Genet 36:15S

13. Elroy-Stein O, Bernstein Y, Groner Y 1986 Overproduction of human $\mathrm{Cu} /$ $\mathrm{Zn}$-superoxide dismutase in transfected cells: extenuation of paraquat-mediated cytotoxicity and enhancement of lipid peroxidation. EMBO J 5:615622

14. Brooksbank BWL, Martinez M, Balazs R 1985 Altered composition of polyunsaturated fatty acyl groups in phosphoglycerides of Down's syndrome fetal brain. J Neurochem 44:869-874

15. Epstein CJ 1981 Animal models for human trisomy. In: de la Cruz FF, Gerald PS (eds) Trisomy 21 (Down Syndrome). Research Perspectives. University Park Press, Baltimore, pp 263-273

16. Epstein CJ 1986 The Consequences of Chromosome Imbalance: Principles, Mechanisms and Models. Cambridge University Press, New York

17. Epstein CJ, Cox DR, Epstein LB 1985 Mouse trisomy 16: An animal model of human trisomy 21 (Down syndrome). Ann NY Acad Sci 450:157-168

18. Cox DR, Epstein LB, Epstein CJ 1980 Genes coding for sensitivity to interferon (IfRec) and soluble superoxide dismutase (SOD-1) are linked in mouse and man and map to mouse chromosome 16. Proc Natl Acad Sci USA 77:21682172

19. Lin PF, Slate DL, Lawyer FC, Ruddle FH 1980 Assignment of the murine interferon sensitivity and cytoplasmic superoxide dismutase genes to chromosome 16. Science 209:285-287

20. Cox DR, Goldblatt D, Epstein CJ 1981 Chromosomal assignment of mouse PRGS: further evidence for homology between mouse chromosome 16 and human chromosome 21. Am J Hum Genet 33:145A

21. Watson DK, McWilliams-Smith MJ, Kozak C, Reeves R, Gearhart J, Nunn MF, Nash W, Fowle JR III, Duesberg P, Papas TS, O'Brien SJ 1986 Conserved chromosomal positions of dual domains of the ets protooncogene in cats, mice, and humans. Proc Nat Acad Sci USA 83:1792-1796

22. Miyabara S, Gropp A, Winking H 1982 Trisomy 16 in the mouse fetus associated with generalized edema, cardiovascular and urinary tract anomalies. Teratology 25:369-380

23. Epstein CJ 1985 The mouse trisomies: Experimental systems for the study of aneuploidy. In: Kalter $\mathrm{H}$ (ed) Issues and Reviews in Teratology, Vol 3. Plenum, New York, pp 171-217

24. Epstein CJ 1985 Mouse monosomies and trisomies as experimental systems for studying mammalian aneuploidy. Trends Genet 1:129-134

25. Oster-Granite ML, Gearhart JD, Reeves RH 1986 Neurobiologial consequences of trisomy 16 in the mouse. In: Epstein CJ (ed) The Neurobiology of Down Syndrome. Raven Press, New York, pp 137-151

26. Coyle JT, Gearhart JD, Oster-Granite ML, Singer HL, Moran TH 1986 Brain neurotransmitters: implications for Down syndrome from studies of mouse trisomy 16. In: Epstein CJ (ed) The Neurobiology of Down Syndrome. Raven Press, New York, pp 153-169

27. Epstein CJ, Hofmeister BG, Yee D, Smith SA, Philip R, Cox DR, Epstein LB 1985 Stem cell deficiencies and thymic abnormalities in fetal mouse trisomy 16. J Exp Med 162:695-712

28. Gropp A, Kolbus U, Giers D 1975 Systematic approach to the study of trisomy in the mouse. Cytogenet Cell Genet 14:42-62

29. Lowry DH, Rosenrough NJ, Farr AL, Randall RJ 1951 Protein measurement with the Folin phenol reagent. J Biol Chem 193:265-275

30. Weil J, Epstein CJ 1979 The effect of trisomy 21 on the patterns of polypeptide synthesis in human fibroblasts. Am J Hum Genet 31:478-488

31. Salin ML, McCord JM 1974 Superoxide dismutase in polymorphonuclear leukocytes. J Clin Invest 54:1005-1009

32. Fried R 1975 Enzymatic and non-enzymatic assay of superoxide dismutase. Biochimie 57:657-660

33. Paglia DE, Valentine WN 1967 Studies on the quantitative and qualitative characterization of erythrocyte glutathione peroxidase. J Lab Clin Med 70:158-169

34. Boehme DH, Kosecki R, Carson S, Stern F, Marks N 1977 Lipid peroxidation in human and rat brain tissue: developmental and regional studies. Brain Res 136;11-21

35. Halliwell B, Gutteridge JMC 1985 Free Radicals in Biology and Medicine Clarendon Press, Oxford

36. Gerdin E, Tydén O, Eriksson UJ 1985 The development of antioxidant enzymatic defense in the perinatal rat lung. Activities of superoxide dismutase, glutathione peroxidase, and catalase. Pediatr Res 19:687-691

37. Kellogg EW, Fridovich I 1976 Superoxide dismutase in the rat and mouse as a function of age and longevity. J Gerontol 31:405-408

38. Mavelli I, Rigo A, Federico R, Ciriolo MR, Rotilio G 1982 Superoxide dismutase, glutathione peroxidase and catalase in developing rat brain. Biochem J 204:535-540 